\title{
Consequences from use of reminiscence - a randomised intervention study in ten Danish nursing homes
}

\author{
Claire Gudex*1, Charlotte Horsted ${ }^{1}$, Anders Møller Jensen², Marianne Kjer ${ }^{3}$ and Jan Sørensen ${ }^{1}$
}

\begin{abstract}
Background: Reminiscence is the systematic use of memories and recollections to strengthen self-identity and selfworth. The study aim was to investigate the consequences for nursing home residents and staff of integrating reminiscence into daily nursing care.

Methods: In this randomised study, ten nursing homes were matched into two groups on the basis of location, type and size. In the period August 2006 - August 2007, staff in the Intervention Group were trained and supported in the use of reminiscence, involving individual and group sessions with residents as well as reminiscence boxes, posters and exhibitions. At baseline and again 6 and 12 months after the intervention start, data were collected on residents' cognitive level, agitated behaviour, general functioning and proxy-assessed quality of life, as well as on staff well-being and job satisfaction. Mixed linear modelling was used to analyse differences in outcome between the intervention and control groups.
\end{abstract}

Results: Project drop-out rates were 32\% for residents and 38\% for nursing staff. Most staff in the Intervention Group considered reminiscence a useful tool that improved their communication with residents, and that they would recommend to other nursing homes. There were no significant differences between residents in the Intervention and the Control Group in cognitive level, agitated behaviour or general functioning. Residents in the Intervention Group showed significant higher score at 6 months in quality of life subscale 'Response to surroundings', but there was no significant difference at 12 months.

Positive effects of reminiscence were observed for all staff outcome measures, the only exception being SF-12 selfrated physical health. At 6 months after start of reminiscence, staff in the Intervention Group had significantly better scores than those in the Control Group for Personal accomplishment, Emotional exhaustion, Depersonalisation, 'Attitude towards individual contact with residents' and SF-12 self-rated mental health. At 12 months after start of reminiscence, staff in the Intervention Group had significantly better scores than those in the Control Group for Emotional exhaustion and 'Professional role and development'.

Conclusions: The use of reminiscence appeared to have little long-term effect on the nursing home residents. Nursing staff in the Intervention Group experienced greater satisfaction with professional roles and developed a more positive view of the residents.

International Standard Randomised Controlled Trial Number Register: ISRCTN90253170.

\footnotetext{
*Correspondence: cgudex@mail.dk

${ }^{1}$ CAST - Centre for Applied Health Services Research \& Technology

Assessment, University of Southern Denmark, J.B. Winsløws Vej 9B, 5000 Odense C, Denmark

Full list of author information is available at the end of the article
}

○ 2010 Gudex et al; licensee BioMed Central Ltd. This is an Open Access article distributed under the terms of the Creative Commons BH. Wed Central Attribution License (http://creativecommons.org/licenses/by/2.0), which permits unrestricted use, distribution, and reproduction in any medium, provided the original work is properly cited. 


\section{Background}

A major change in the Danish elderly sector over the last several years is the greater focus on providing services that support the maintenance of the elderly person's personal integrity and self-identify [1]. This is in part derived from psychologist Tom Kitwood's theories regarding person-centred care of people with dementia [2]. A central message here is that emotions and experiences should play a major role in the interaction between the person with dementia and the carer, and the uniqueness of each individual's experience must always be taken into account. An understanding of the behaviour and reactions of the person with dementia is crucial in ensuring that the most appropriate interaction will occur.

Reminiscence is an approach that nursing home staff can use to strengthen residents' feelings of self-identity, and an introduction to the method is now included in many training courses for nursing home staff in Denmark. Reminiscence can be described as 'the systematic use of memories and recollections to reawaken or strengthen self-identity and self-worth' (translated from [3]). The approach has its basis in Robert Butler's work on 'life review' [4]. However, while life review is an intrapersonal approach undertaken only at individual level with an aim to resolve internal conflicts stemming from past experiences [5], reminiscence is an interpersonal approach undertaken either at individual level or group level with the aim of eliciting and sharing pleasant memories and experiences in an informal and conflict-free manner.

The rationale behind the use of reminiscence is thus an attempt to [6-9]:

- Strengthen feelings of the individual's identity and self-worth

- Re-establish feelings of coherence and control over one's own life

- Encourage the individual to (continue to) value his/ her own life and to remember and re-experience happy events and associated positive feelings.

Reminiscence can be beneficial for elderly people with depressive symptoms. A meta-analysis [10] of 20 studies (of which 15 were RCTs) found that the effect size of reminiscence was equivalent to that of antidepressive medication and cognitive behavioural therapy.

Reminiscence is also expected to benefit elderly people with dementia. Although individuals with advanced dementia have often lost the ability to actively consider their past, their distant memory is often intact as is the ability to develop relationships and interact with their environment [11]. A Cochrane meta-analysis [12] of four randomised controlled studies found some evidence for improved cognitive function and fewer depressive symptoms among elderly people with dementia who had participated in reminiscence, but also noted that methodological deficiencies (such as small study samples and non-blind assessments) and the large variation in the reminiscence approaches used prevented robust conclusions. Other studies of the use of reminiscence among elderly with dementia have reported minor improvements in social functioning and less problem behaviour [7] and no difference in agitated behaviour (compared to a group undergoing stimulation therapy) [13]. In determining the impact of reminiscence, it is important to take account of individual differences among residents such as level and type of dementia, communication skills and environmental context [14].

Few studies have investigated the effect of reminiscence on nursing staff. In two studies where reminiscence was only one of several approaches implemented in the intervention group, small improvements were found in job satisfaction and stress levels $[15,16]$. Reminiscence has also been reported to increase the nursing staff's knowledge of the residents' life history, leading to the staff finding it easier and more enjoyable to talk with the residents about personal topics $[17,18]$.

Given the lack of a standard approach to reminiscence in the elderly sector, and limited evidence from large randomised studies, the aim of the current study was to use an RCT approach to investigate the consequences for nursing home residents and staff of integrating reminiscence into daily nursing care, i.e.

- Consequences for residents in terms of quality of life, agitated behaviour and cognitive and physical function

- Consequences for staff in terms of job satisfaction, stress/burnout and health status.

The specific study questions were whether use of reminiscence could:

i) Reduce (and perhaps reverse) the deterioration that one could expect to see over time in the functional level of nursing home residents, and especially those with low cognitive function

ii) Improve the staff's assessment of their satisfaction with nursing care and their work situation, work-related burnout and own (mental) health.

The reminiscence approach used in the current study builds further on the approach used by the Danish Centre for Reminiscence (Nørrebro Erindringscenter). Greater emphasis has been given to categorising reminiscence as general, specific or spontaneous, however, in order to illustrate to the nursing staff that reminiscence can be used in a wide range of situations, also without preplanned sessions or tours out of the home.

\section{Methods}

The study was undertaken as a randomised, matched intervention study. Ten nursing homes were matched by the project team into two groups on the basis of location (municipality, urban/rural), type (traditional institutional 
multi-storey building with long corridors vs. home-like units with central communal rooms) and size (under and over 45 residents). The two lists of five nursing homes were then placed in two blank sealed envelopes; a colleague external to the project group was asked to arbitrarily choose one envelope; the five nursing homes named in this envelope became the Intervention Group (IG), who implemented reminiscence. The remaining five nursing homes became the Control Group (CG), who continued with usual nursing care. Nursing homes were not told of their group until after the second baseline data collection was completed. Blinding of nursing staff with respect to intervention was not possible, although the project interviewers were not formally informed of which group the nursing homes were in.

Because the variation in resident characteristics between nursing homes was unknown, sample size calculations were made at individual level i.e. according to resident characteristics rather than nursing home characteristics. These indicated that approximately 350 residents would be required to enter the study in order to achieve statistical significant results. This was based on the following assumptions:

- That a reduction in residents' agitated behaviour, as measured by the Cohen-Mansfield Agitation Inventory (CMAI), was the primary outcome

- That a change of 4.15 in CMAI score represented a clinically relevant effect [19]

- A CMAI score standard deviation of 16.8 [20]

- That $30 \%$ of residents would drop out over the course of the study due to worsening health and death

- A significance level of $5 \%$ and power of $80 \%$.

\section{Recruitment of participants}

A previous study [21] had shown that nursing homes in the region had an average size of 35 residents; the aim was thus to recruit ten nursing homes that did not already use reminiscence on a systematic basis. In August 2005 letters of invitation were sent to 35 municipalities in the Mid-Jutland Region where there was at least one nursing home with a minimum 35 residents; these letters were followed up by personal visits to explain the nature and aim of the project. Twenty-six municipalities declined to participate and a further two were excluded due to extensive building projects and/or staff training in the area. From the remaining seven municipalities there were 14 nursing homes that were willing to be randomised; four of these were excluded after closer examination (two nursing homes already used reminiscence in daily care, one was under new management and the fourth had recently undergone extensive staff training). The ten participating nursing homes were all publicly owned and at recruitment (February 2006) had a total of 447 residents. Nursing home managers were requested not to undertake any major organisational or staff-related changes over the course of the project.

All residents who lived permanently in the nursing home were included in the study, with the following exceptions: i) residents with advanced dementia living in protected-environment units within the nursing homes; these were typically small units with specialised nursing staff who already used reminiscence in daily care, ii) residents who were bed-ridden or terminally ill (8), were on short-term placement or waiting to move to a protectedenvironment unit (5), or were known to become aggressive in new situations (2). The nursing staff informed residents individually both orally and in writing about the study and asked for signed consent; all relatives/visitors were also informed of the study and were asked for consent in cases where the resident was unable to give it.

All permanent nursing staff involved in the daily personal care of the residents were included in the study, i.e. nurses, nurse aids and occupational therapists. Administrative and service staff were excluded. All the nursing staff in the Intervention Group were expected to participate in reminiscence training and to implement the method in their daily work.

\section{Intervention}

Nursing home staff in the Intervention Group attended a standardised course in reminiscence (two whole and two half-days over a 9-month period) that comprised formal teaching, group work and discussion sessions (conducted by MK). During the intervention period (August 2006 August 2007) nursing staff were expected to use three forms of reminiscence:

- General reminiscence: group sessions run by 1-2 nurses for typically 2-8 residents with similar backgrounds or interests; structured around a chosen theme, often based on a reminiscence box containing a variety of tools, photos, books, music etc. and involving senses of sight, touch, smell, hearing.

- Specific reminiscence: sessions for 1-2 residents structured around a theme and tailored to the individual resident's communication needs; often using family photos, reminiscence games and activities e.g. baking.

- Spontaneous reminiscence: informal use of comments during regular daily activities (e.g. dressing, meal-times, preparing for bed) to elicit a resident's memories of earlier life experiences; can start as an individual contact that spreads to involve others sitting nearby.

Immediately after each general and specific reminiscence session, the participating staff assessed each resident's level of engagement according to a 5-point scale.

Reminiscence themes used included childhood, kitchen and housework, rural life, family life, occupations, leisure activities and traditions; sessions could also take the form of games and tours to local historical buildings and muse- 
ums. Thirty reminiscence boxes were circulated between the five IG nursing homes during the intervention period. These boxes could also be used to make small exhibitions, which could be visited by staff, residents and visitors (Figure 1). Posters showing historical objects were also made available to each nursing home.

Separate meetings were held (by MK and AM) with each nursing home's management and selected project contact persons in order to ensure support and a coordinated effort for reminiscence activities. A reminiscence trainer (AM) visited each nursing home 5-8 times during the intervention period to provide guidance and encouragement in the use of reminiscence material and activities.

The importance of documenting the individual resident's life history was emphasised to both staff and relatives, with examples to illustrate how knowledge of previous life experiences could be used to make contact with residents, to determine meaningful activities for the resident and to help residents express their thoughts and feelings.
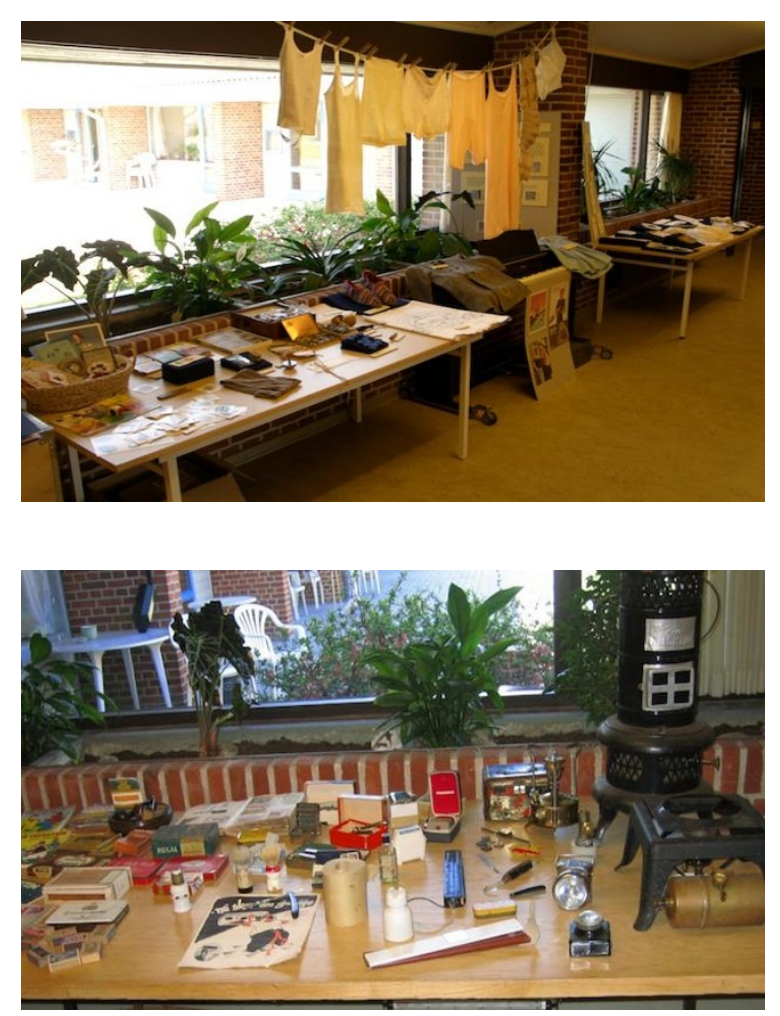

Figure 1 Examples of reminiscence exhibitions. The ladies' exhibition 'Darning and embroidery' included a home-sewn and darned child's coat, button box, embroidery patterns, crocheted collars, lace handkerchiefs, sewing box, washing line and pegs. The gentlemen's exhibition included shaving equipment, old electrical plugs, rationing stamps, technical books, primus stove, a peat cutter and a knife-grinder's cycle.

\section{Data collection}

Baseline data were collected among residents in March, May and August 2006. Data collection was repeated 6 and 12 months after start of reminiscence training, i.e. March and August 2007. Selection of instruments was based on relevance for an institutionalised population, wide use with a validated version available in Danish, and practical ease of completion. The instruments were tested in a pilot study prior to the main study.

At the first baseline data collection, nursing staff completed the questionnaires on residents' agitated behaviour, quality of life and general level of functioning together with a project interviewer. Hereafter the nursing staff completed the questionnaires themselves. Project interviewers assessed resident's cognitive level. The six interviewers were nurses and/or community dementia coordinators; they attended a training day where they were instructed in the use of the questionnaires and cognitive tests.

Nursing staff completed a questionnaire about workrelated burnout, job satisfaction and own health four times in the course of the study, i.e. March and August 2006 (baseline) and March and August 2007 (6 months and 12 months after start of reminiscence training, respectively).

\section{Outcome measures}

CMAI (Cohen-Mansfield Agitation Inventory) assesses the frequency of 29 types of agitated behaviour within the previous two weeks, as well as how disturbing these behaviours are for other residents and staff [22]. Frequency of each behaviour is scored from 0 (Never) to 6 (Several times an hour); responses for the individual behaviours are summed to give a total Frequency score between 0 and 174 [23]. Four subscale scores can be calculated for physically aggressive and non-aggressive behaviour and verbally aggressive and non-aggressive behaviour, respectively. Disturbance is scored from 0 (Not at all disturbing) to 4 (Extremely disturbing); responses for the individual behaviours are summed to give a total Disturbance score between 0 and 116 [24]. A higher score reflects more frequent or disturbing agitated behaviour.

ADRQL (Alzheimer Disease Related Quality of Life) was developed to assess the quality of life of people with Alzheimer's disease, but is also used with other forms of dementia. It comprises 47 items categorised under five domains: social interaction, awareness of self, response to surroundings, enjoyment of activities and feelings/mood [25]. The Yes/No responses to each item are weighted; both the total score and the five subscale scores are expressed as a percentage of the total possible score and range between 0 and 100. A higher score reflects better quality of life for the individual resident (as perceived by 
the nursing staff). As the ADQRL was not available in Danish, it was translated by the project group using forward and backward translation followed by testing in the pilot study [26].

GBS (Gottfries-Bråne-Steen scale) assesses the general functioning of people with dementia and comprises 27 items categorised under intellectual, emotional and ADL (activity of daily living) impairments, as well as symptoms of dementia [27]. Responses (0 to 6) to the items are summed to subscale scores and to an overall score that ranges between 0 and 162. A higher score reflects a lower level of functioning.

MMSE (Mini-Mental State Examination) measures cognitive function, including orientation in time and place, recall, language, attention and calculation. The score for each item is summed to a total score that ranges between 0 and 30. A higher score reflects better cognitive function; a score of 24-30 is considered normal, score 1823 reflects mild cognitive deterioration and score under 18 reflects severe cognitive deterioration [28].

SIB-S (Severe Impairment Battery - Short Form) was used with residents who had a MMSE score less than 15, as MMSE is a less sensitive measure for people with severe dementia. The original SIB instrument has 51 items [29]; the same authors have developed the short version, that has 25 items with a total score ranging between 0 and 50 [30]. A higher score reflects better cognitive function (though still in the lowest levels of cognitive functioning)

MBI-HSS (Maslach Burnout Inventory - Human Services Survey) assesses burnout among people who work professionally with others, including those in the health services [31]. The 22 items (each with six response categories ranging from 'never' to 'every day') are categorised into three subscales: personal accomplishment (scale from 0 to 48, where a high score reflects feelings of competence and successful work achievement), emotional exhaustion (scale from 0 to 54, where a high score reflects feelings of being emotionally overextended and exhausted by one's work) and depersonalisation (scale from 0 to 30, where a high score reflects an insensitive and impersonal response towards recipients of one's care).

SNCW (Satisfaction with Nursing Care and Work Assessment) scale comprises 34 items (each with five response categories ranging from 'strongly agree' to 'strongly disagree') relating to work environment and personal development [32,33]. Only 11 items were used in the current study, as the others were covered by the other instruments. The original Swedish instrument was translated to Danish using forward translation followed by testing in the pilot study. Factor analysis was then used to categorise the $11 \mathrm{SNCW}$ items into dimensions; four dimensions were identified: Professional role and development, Work environment and staff collaboration, Residents' level of care and Individual contact with residents. The lower the score, the greater the level of satisfaction with nursing care and work or the more positive the staff attitude.

SF-12v2 (Short Form-12 version 2) is a generic measure of health status comprising 12 items; scores can be calculated for self-assessed physical health (PCS) and mental health (MCS), where the average score for the general population is set at $50[34,35]$. A score over 50 implies that own health is assessed as better than average. The question on general health perception asks 'In general, would you say your health is excellent, very good, good, fair or poor?'

Staff experiences with the actual implementation of reminiscence were further investigated in two ways: i) through additional items in the staff questionnaire, that only the IG group answered, and ii) through personal interviews with 14 selected staff members in the IG group, conducted by $\mathrm{CH}$ and $\mathrm{CG}$ at the end of the study. A semi-structured interview guide was used to enquire about staff attitudes towards the reminiscence activities and their impact on staff and residents, the level of implementation of reminiscence and the prerequisites for a successful implementation. The informants, who were selected by the manager of each nursing home, came from different units within the home and included staff with both positive and more negative attitudes towards the implementation of reminiscence.

\section{Statistical analysis}

There were few missing data (under 4\%) on instrument items. Missing data on ADRQL items were adjusted for as recommended by the instrument's developers. Missing data on other instrument items meant that total scores could not be calculated; data for these respondents were thus excluded from the analysis of instrument scores.

Differences between IG and CG at baseline were assessed using Chi-squared test or Fisher's exact test for categorical variables, $\mathrm{t}$-tests for continuous normally distributed data and Mann-Whitney test for continuous non-normally distributed data.

Mixed linear modelling was used to analyse differences in outcome between the intervention and control groups while taking account of intra-individual correlations; this approach is fairly robust to missing observations, which are assumed to be missing at random [36-38]. The outcome scores were treated as continuous dependent variables. The covariates used in the main model were: randomisation to intervention group (iv $=1$ ), time of observation (baseline BL1, BL2 and BL3 (reference) and T6 and T12 i.e. 6 and 12 months after start of reminis- 
cence) and interaction variables $\mathrm{T} 6 \% \mathrm{iv}$ and $\mathrm{T} 12 \% \mathrm{iv}$. The estimated models allowed each participant to deviate from the overall mean score (random intercept model). Early analysis identified significant differences in score development for residents with normal cognitive functioning (MMSE > 23) in comparison to residents with cognitive impairment; an indicator variable for cognitive function (normal at baseline $3=1$ ) was thus also included as a covariate in the outcome analysis for residents. Further models were estimated to allow both intercept and slope variations for the interaction variables; these did not improve the model fit, however, and are not reported here. The linear mixed modelling was carried out using STATA version 11 . A $5 \%$ level of significance was used.

\section{Results}

\section{Characteristics of nursing home residents}

In total, 52 residents (or the family on behalf of the resident) declined to participate in the study and a further 32 dropped out before the baseline data collection, leaving 348 residents (Figure 2). The drop-out rate over the project period was $32 \%$ for residents. Of the 111 residents who failed to complete the study, 98 had died, 11 had moved out of the nursing home, 1 withdrew study participation and 1 had become too ill. There were no significant differences in sociodemographic characteristics between the 348 residents who started the study and the 237 residents who completed the study (Table 1). Dropout rates were similar in IG and CG.

There were no significant differences between residents in IG and CG at baseline with respect to sociodemographic variables or scores for agitated behaviour, quality of life, general functioning or cognitive function. According to the baseline MMSE score, approximately half (47\%) of the residents had severe cognitive impairment (score < 18 ) and $24 \%$ had normal cognition (score $>23$ ).

\section{Effect of reminiscence on residents}

Tables 2 and 3 present the estimated parameters and confidence intervals from the mixed modelling analysis of outcomes for residents.

\section{a) Agitated behaviour (CMAl)}

- Agitated behaviour was more frequent over time for both groups and was significantly more frequent at 12 months. Residents in IG had less frequent agitated behaviour at 12 months than CG, but this difference was not significant.

- Perceived disturbance from agitated behaviour showed no change over time, and there were no differences between IG and CG.

- Normal cognitive score at baseline (MMSE > 23) was significantly associated with less frequent agitated behaviour and less perceived disturbance from agitated behaviour.

\section{b) Quality of life (ADRQL)}

- Quality of life scores worsened over time for both groups and the reduction after 12 months was significant. There were no differences in score change over time between IG and CG.

- The subscale 'Response to surroundings' showed a significant higher score at 6 months for IG than for CG, but no significant difference between IG and CG at 12 months (Table 3).

- No significant differences between IG and CG were indentified on the other four subscales.

- Normal cognitive score at baseline (MMSE > 23) was significantly associated with higher quality of life score.

\section{c) General functioning (GBS)}

- GBS score showed deterioration over time in both groups and showed significant deterioration at 12 months. There were no significant differences between IG and CG.

- Normal cognitive score at baseline (MMSE > 23) was significantly associated with better general functioning.

\section{d) Cognitive function (MMSE and SIB-S)}

- There was deterioration in cognitive function over time in both groups and this was significant for SIB-S (and close to significance for MMSE). Regarding residents with lower baseline cognitive function (i.e. where SIB-S was used to assess cognitive function), those in IG showed a higher score at 6 months than residents in CG, although this difference was not significant.

There were no significant differences in score change on any instrument between residents who participated in many reminiscence sessions and residents who participated in fewer sessions, even after taking baseline cognitive function into account (data not shown).

According to the staff assessments, residents participating in the reminiscence sessions typically showed 'clear signs of interest, engagement or enjoyment' or 'varying interest, mostly positive'; very few residents became angry or irritable during the sessions. There was no consistent pattern in individual resident's level of engagement in reminiscence sessions over the study period. The association between level of engagement and score change was thus not explored.

\section{Characteristics of nursing home staff}

The drop-out rate over the project period was $38 \%$ for nursing staff. Of the 135 staff who failed to complete the study, 111 were no longer working at the nursing home and 24 did not complete follow-up questionnaires (Figure $3)$. There were no significant differences in either sociodemographic characteristics or instrument scores (SF-12 and MBI-HSS) between the 353 nursing staff who participated at baseline and the 218 staff who completed the study. Drop-out rates were similar in IG and CG (overall 


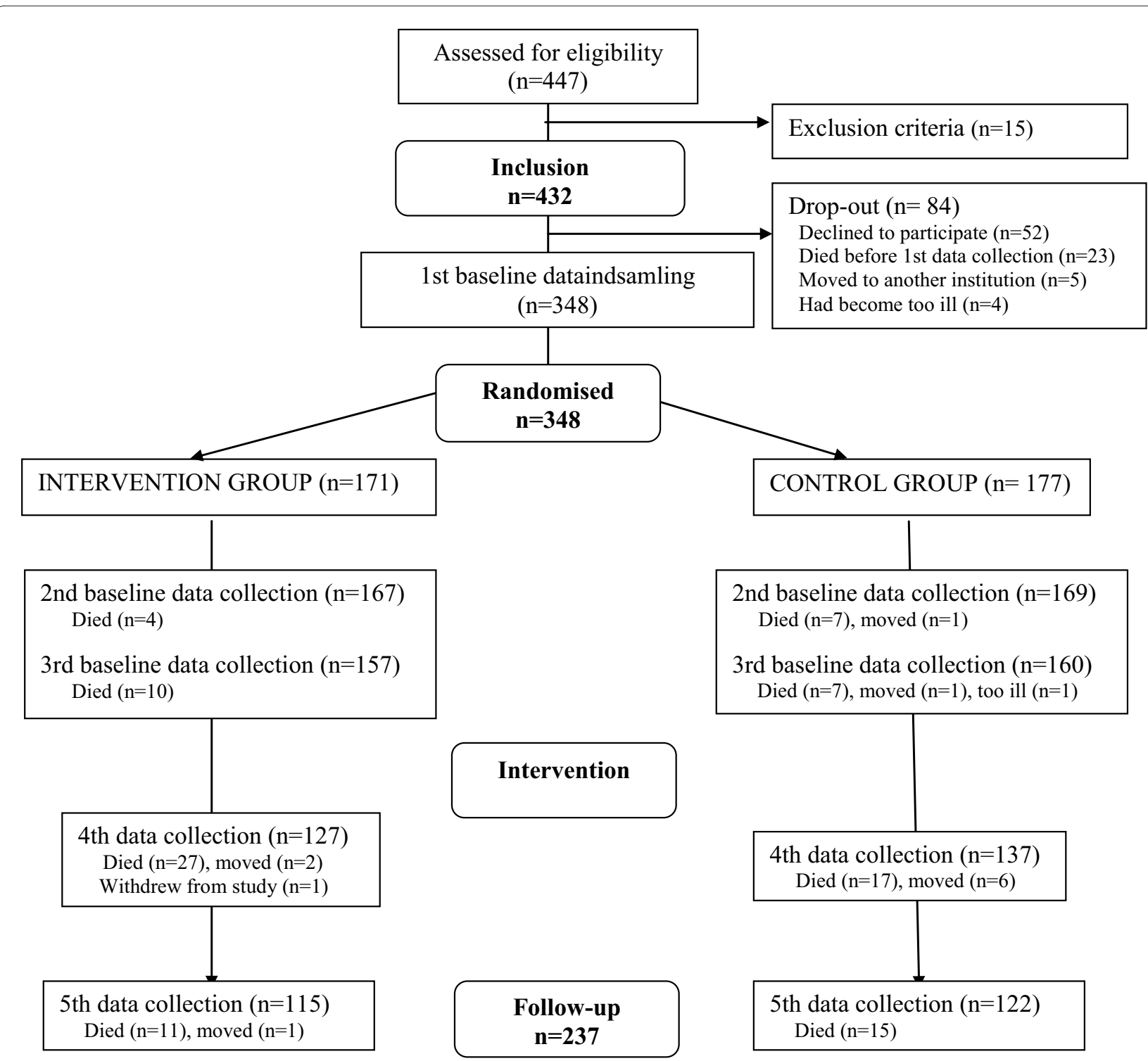

Figure 2 Flow chart of nursing home residents' participation in the reminiscence study

mean $38.2 \%$ ), but there was large variation across nursing homes, ranging between $14 \%$ and $62 \%$.

The average age of the nursing staff (of whom 97\% were women) was 47 years and the average length of employment in the nursing home 8 years. Most (87\%) were nurse aids ( 1.5 years' training) or nurse assistants (3 years' training); the remainder were nurses (3.5 years' training) and therapists. Staff in CG had been employed longer than those in IG (10.1 vs. 6.1 years, $\mathrm{p}<0.001)$ - presumably because more of the homes in IG were relatively new; otherwise there were no significant differences between the staff in IG and CG.

At baseline approximately half of the nursing staff respondents rated their own health as 'excellent' or 'very good'; under $10 \%$ rated it as 'poor' or 'fair'; there were no significant score differences between staff in IG and CG. According to the baseline MBI-HSS scores, most of the staff respondents experienced high personal accomplishment (77\%), low emotional exhaustion (75\%) and low depersonalisation (91\%). Staff in IG reported significantly higher baseline emotional exhaustion than staff in CG (mean score $\mathrm{IG}=13.0$ vs. $\mathrm{CG}=10.4 ; \mathrm{p}=0.035$ ), as well as a significantly worse score on the SNCW-derived domain of Work environment \& staff collaboration (IG $=2.7$ vs. $\mathrm{CG}=2.1, \mathrm{p}=0.004)$.

\section{Effect of reminiscence on staff}

Tables 4 and 5 present the estimated parameters and confidence intervals from the mixed modelling analysis of outcomes for staff. 
Table 1: Characteristics of all participating residents and those who completed the study.

\begin{tabular}{|c|c|c|}
\hline & $\begin{array}{l}\text { Baseline } \\
(n=348)\end{array}$ & $\begin{array}{c}\text { Study } \\
\text { completion } \\
(n=237)\end{array}$ \\
\hline Women & $68 \%$ & $68 \%$ \\
\hline Mean age (s.d.) & 82.3 yrs (9.5) & 81.9 yrs (9.8) \\
\hline Mean (s.d.) length of residence & $2.1 \mathrm{yrs}(3.1)$ & $2.3 \mathrm{yrs}(3.3)$ \\
\hline $\begin{array}{l}\text { On dementia medication within the } \\
\text { past year }\end{array}$ & $8 \%$ & $6 \%$ \\
\hline Has dementia diagnosis & $19 \%$ & $18 \%$ \\
\hline $\begin{array}{l}\text { Reduced physical mobility (incl. } \\
\text { wheelchair use) }\end{array}$ & $77 \%$ & $73 \%$ \\
\hline $\begin{array}{l}\text { Treated for depression within past } 1 \\
\text { year }\end{array}$ & $47 \%$ & $45 \%$ \\
\hline
\end{tabular}

\section{a) Level of work-related burnout (MBI-HSS)}

- Staff in IG had a significantly better score on personal accomplishment at 6 months, but there was no significant difference from staff in CG at 12 months.

- Staff in IG had a significantly better score on emotional exhaustion than staff in CG at both 6 months and 12 months.
- Staff in IG had a significantly better score on depersonalisation at 6 months, but there was no significant difference from staff in CG at 12 months.

b) Satisfaction with work (domains from SNCW items)

- Professional role and development: Staff in IG had a significantly better score than staff in CG at 12 months, though not at 6 months.

- Work environment and staff collaboration: Staff in IG had a higher score than staff in CG at 12 months and this difference was close to significance. There was no difference between IG and CG at 6 months.

- Attitude towards residents' level of care: Staff in IG had a higher score than staff in CG at 12 months and this difference was close to significance. There was no difference between IG and CG at 6 months.

- Attitude towards individual contact with residents: Staff in IG had a significantly better score than staff in CG at 6 months; at 12 months the score was again higher but the difference was not significant.

c) Self-rated health (SF12-v2)

- With respect to self-rated physical health there were no significant changes over time and no differences between IG and CG.

- With respect to self-rated mental health, staff in IG had a significant better score than CG at 6 months, but

Table 2: Results of mixed modelling analysis of outcome scores for residents in the Intervention and Control Groups.

\begin{tabular}{|c|c|c|c|c|c|c|}
\hline & $\begin{array}{c}\text { Frequency of } \\
\text { agitated behaviour } \\
\text { (CMAI) }\end{array}$ & $\begin{array}{c}\text { Disturbance } \\
\text { from agitated } \\
\text { behaviour } \\
\text { (CMAI) }\end{array}$ & $\begin{array}{l}\text { Quality of life } \\
\text { (ADRQL) }\end{array}$ & $\begin{array}{c}\text { General } \\
\text { functioning (GBS) }\end{array}$ & $\begin{array}{c}\text { Cognitive } \\
\text { function (MMSE) }\end{array}$ & $\begin{array}{c}\text { Cognitive function } \\
\text { (SIB-S) }\end{array}$ \\
\hline BL1 & $1.7(0.7 ; 2.7)$ & $0.8(-0,3 ; 1.8)$ & $0.2(-0.9 ; 1.4)$ & $-4.7(-6.7 ;-2.7)$ & $-0.4(-0.8 ; 0.1)$ & $0.2(-1.8 ; 2.1)$ \\
\hline $\mathrm{BL} 2$ & $-0.2(-1.1 ; 0,8)$ & $-0.2(-1,3 ; 0.9)$ & $0.2(-0.9 ; 1.4)$ & $-2.6(-4.6 ;-0.6)$ & Not measured & Not measured \\
\hline BL3 & Reference & Reference & Reference & Reference & Reference & Reference \\
\hline T6 & $1,0(-0,4 ; 2,4)$ & $0.9(-0.6 ; 2.5)$ & $-0.3(-1.9 ; 1.3)$ & $2.6(-0.2 ; 5.4)$ & Not measured & $-3.8(-6.5 ;-1.2)$ \\
\hline $\mathrm{T} 12$ & $1.5(0.1 ; 3.0)$ & $0.3(-1.3 ; 1.8)$ & $-2.1(-3.7 ;-0.5)$ & $5.2(2.3 ; 8.1)$ & $-0.6(-1.3 ; 0.1)$ & $-3.8(-6.6 ;-0.9)$ \\
\hline iv & $1.2(-1.1 ; 3.4)$ & $-0.0(-1.6 ; 1.6)$ & $-1.4(-4.0 ; 1.1)$ & $-1.0(-6.7 ; 4.7)$ & $-0.1(-1.3 ; 1.1)$ & $-1.7(-6.5 ; 3.1)$ \\
\hline T6*iv & $0.1(-1.8 ; 1.9)$ & $-1.0(-2.9 ; 1.0)$ & $0.7(-1.4 ; 2.8)$ & $-2.0(-5.6 ; 1.6)$ & Not measured & $3.2(-0.4 ; 6.9)$ \\
\hline MMSE > 23 & $-7.6(-10.2 ;-5.1)$ & $-3.7(-5.6 ;-1.8)$ & $12.0(9.0 ; 14.9)$ & $-38.6(-45.2 ;-31.9)$ & $10.8(9.5 ; 12.2)$ & Not applicable \\
\hline Constant & $10.4(8.6 ; 12.2)$ & $6.6(5.2 ; 8.0)$ & $78.8(76.7 ; 80.8)$ & $59.4(55.0 ; 63.9)$ & $15.4(14.4 ; 16.3)$ & $34.7(31.2 ; 38.1)$ \\
\hline $\begin{array}{l}\mathrm{n} \text { (obs/ } \\
\text { residents) }\end{array}$ & $1391 / 342$ & $987 / 304$ & $1476 / 344$ & $1393 / 348$ & $696 / 331$ & $343 / 121$ \\
\hline $\begin{array}{l}\text { Log-restricted } \\
\text { likelihood }\end{array}$ & -4902.8 & -3290.9 & -5429.7 & -5963.5 & -1972.2 & -1259.7 \\
\hline
\end{tabular}

Figures are modelled parameter estimates (95\% confidence intervals).

$\mathrm{BL} 1=$ indicator for baseline $1 ; \mathrm{BL} 2=$ indicator for baseline $2 ; \mathrm{BL} 3=$ indicator for baseline $3 ; \mathrm{T} 6=$ indicator for $\mathrm{t}=6 \mathrm{months}$ after start of intervention; $\mathrm{T} 12$ = indicator for $\mathrm{t}=12$ months after start of intervention; iv = indicator for intervention group; T6iv = interaction between T6 and iv; T12iv = interaction between T12 and iv; MMSE > 23 = indicator for baseline cognitive function in normal range. 
Table 3: Results of mixed modelling analysis of five ADRQL subscores for residents in the Intervention and Control Groups.

\begin{tabular}{|c|c|c|c|c|c|}
\hline & $\begin{array}{c}\text { Socialinteraction } \\
\text { (SI) }\end{array}$ & $\begin{array}{l}\text { Awareness of self } \\
\text { (AS) }\end{array}$ & $\begin{array}{l}\text { Response to } \\
\text { surroundings } \\
\text { (RS) }\end{array}$ & $\begin{array}{l}\text { Enjoyment of } \\
\text { activities (EA) }\end{array}$ & $\begin{array}{l}\text { Feelings/mood } \\
\text { (FM) }\end{array}$ \\
\hline BL1 & $0.2(-1.5 ; 2.0)$ & $3.5(1.5 ; 5.5)$ & $-0.1(-1.7 ; 1.4)$ & $1.9(-1.2 ; 4.9)$ & $-1.8(-3.2 ;-0.3)$ \\
\hline BL2 & $0.7(-1.0 ; 2,5)$ & $-0.4(-2.5 ; 1.6)$ & $0.9(-0.7 ; 2.5)$ & $0.5(-2.6 ; 3.5)$ & $-0.0(-1.4 ; 1.4)$ \\
\hline BL3 & Reference & Reference & Reference & Reference & Reference \\
\hline T6 & $0.7(-1.7 ; 3.2)$ & $-0.1(-3.0 ; 2.7)$ & $-0.3(-2.5 ; 1.9)$ & $-0.7(-5.0 ; 3.6)$ & $-0.6(-2.7 ; 1.4)$ \\
\hline T12 & $-0.6(-3.1 ; 1.8)$ & $-3.5(-6.4 ;-0.6)$ & $-0.1(-2.4 ; 2.1)$ & $-3.1(-7.5 ; 1.3)$ & $-2.6(-4.6 ;-0.5)$ \\
\hline iv & $-1.0(-4.2 ; 2.2)$ & $0.1(-3.6 ; 3.8)$ & $-2.7(-5.5 ; 0.0)$ & $-2.9(-7.8 ; 2.0)$ & $-1.6(-4.4 ; 1.3)$ \\
\hline T6*iv & $-0.7(-3.8 ; 2.4)$ & $0.2(-3.5 ; 3.9)$ & $3.4(0.6 ; 6.2)$ & $-1.0(-6.5 ; 4.6)$ & $1.2(-1.4 ; 3.8)$ \\
\hline T12*iv & $-1.5(-4.8 ; 1.8)$ & $1.3(-2.6 ; 5.1)$ & $0.5(-2.4 ; 3.5)$ & $2.8(-3.0 ; 8.5)$ & $1.1(-1.6 ; 3.8)$ \\
\hline MMSE $>23$ & $10.7(7.1 ; 14.4)$ & $18.2(14.0 ; 22.4)$ & $8.7(5.5 ; 11.8)$ & $20.6(15.1 ; 26.1)$ & $8.1(4.8 ; 11.4)$ \\
\hline Constant & $76.8(74.2 ; 79.5)$ & $68.3(65.2 ; 71.4)$ & $88.5(86.2 ; 90.8)$ & $64.5(60.4 ; 68.4)$ & $86.2(83.9 ; 88.5)$ \\
\hline n(obs/residents) & $1476 / 344$ & $1476 / 344$ & $1473 / 344$ & $1474 / 344$ & $1476 / 344$ \\
\hline $\begin{array}{l}\text { Log-restricted } \\
\text { likelihood }\end{array}$ & -5979.0 & -6211.2 & -5798.2 & -6749.01 & -5732.4 \\
\hline
\end{tabular}

Figures are modelled parameter estimates (95\% confidence intervals).

$\mathrm{BL} 1=$ indicator for baseline $1 ; \mathrm{BL} 2=$ indicator for baseline $2 ; \mathrm{BL} 3=$ indicator for baseline $3 ; \mathrm{T} 6=$ indicator for $\mathrm{t}=6$ months after start of intervention; $\mathrm{T} 12$ = indicator for $\mathrm{t}=12$ months after start of intervention; iv = indicator for intervention group; T6iv = interaction between $\mathrm{T} 6$ and iv; T12iv = interaction between T12 and iv; MMSE > 23 = indicator for baseline cognitive function in normal range.

there was no significant difference from staff in CG at 12 months.

\section{Supplementary findings}

Questionnaire responses from staff in the IG group showed that most were very positive about reminiscence; $90 \%$ considered it to be a good work tool, and many believed that it helped them to communicate with residents $(68 \%)$. Most (76\%) had used reminiscence in a more conscious manner than before, and $85 \%$ would recommend its implementation to other nursing homes.

Many of the IG staff interviewed considered that reminiscence had more of a short-term than a long-term effect. They gave many descriptions of residents who were otherwise withdrawn and quiet but during reminiscence sessions suddenly brightened up and began to talk, often surprising the nursing staff with their skills, knowledge and emotional expression.

Staff in each of the five IG nursing homes commented to the reminiscence trainers that they had become more aware of the contact they had with residents than before the study, and that they felt greater interest in eliciting residents' conversations and reactions. They felt that their use of reminiscence had resulted in a greater level of contact with the residents and more positive experiences. It had also become more natural for them to share personal aspects of their own lives with the residents, e.g. by using their own experiences as starting points for conversation; this had resulted in greater mutual understanding and more equality in their relationship.

\section{Discussion}

The study results show only weak evidence for an effect of reminiscence on the nursing home residents. Reminiscence may have contributed to the observed delay in deterioration of cognitive function at 6 months in residents with moderate cognitive impairment at the start of the study, but no effect of reminiscence on cognitive function was observed after 12 months of intervention. Residents in the Intervention Group showed better scores on the quality of life subscale 'Response to surroundings' at 6 months, but again this difference was not apparent at 12 months. Reminiscence had no apparent effect on residents' agitated behaviour or general functioning.

The study findings show a more positive effect of reminiscence on the nursing home staff, although these effects were only small changes and not all reached statistical significance. Improvements were observed on all staff outcome measures except SF-12 self-rated physical health. At 12-months follow-up, staff in the Intervention Group had lower work-related burnout and greater satisfaction with work, including more positive attitudes towards the residents. 


\section{Exclusion/Drop-out $(\mathrm{n}=31)$}

Mainly due to sick leave, resignation, impending retirement or maternity leave; a small number declined to complete the questionnaire

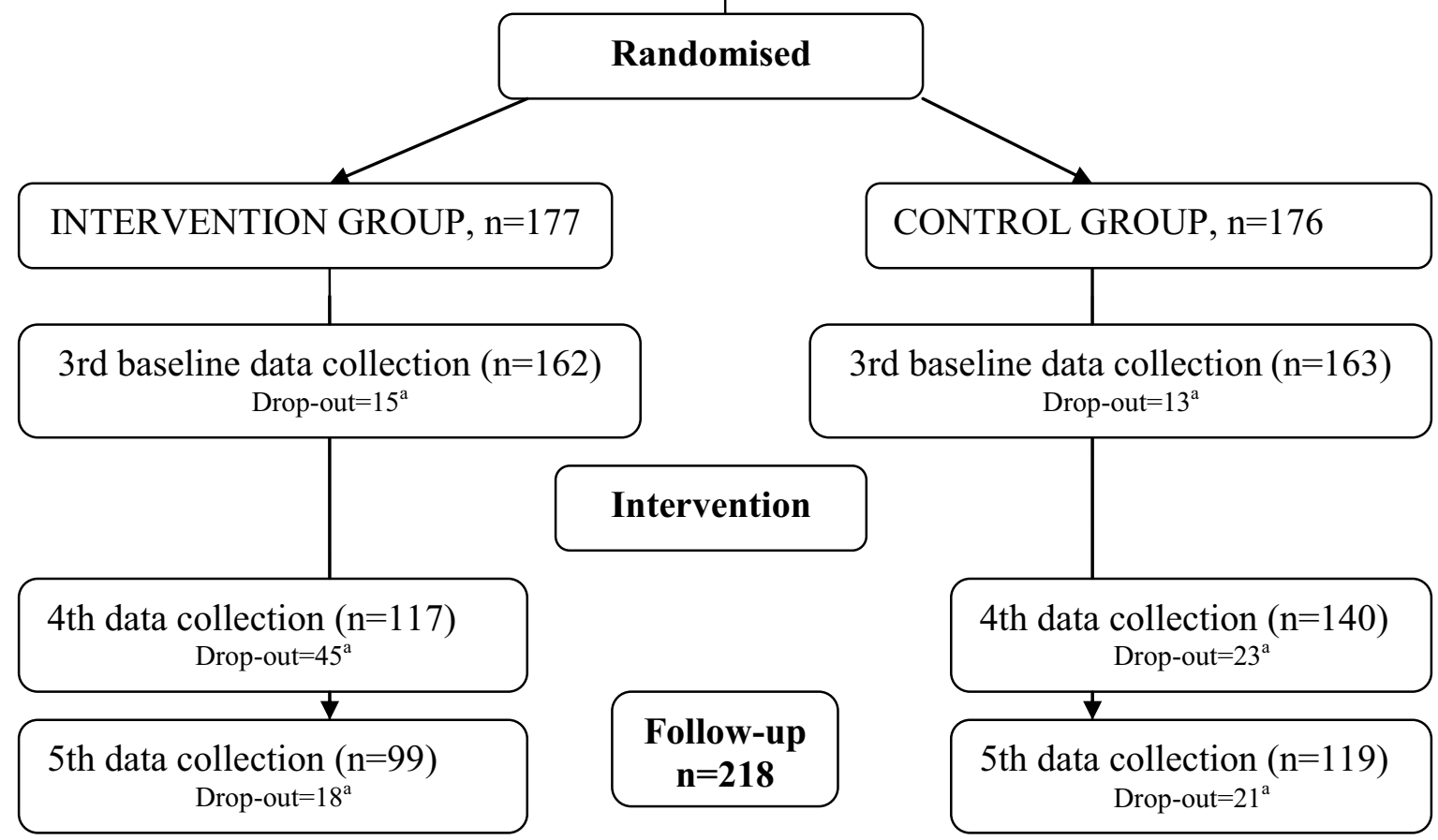

${ }^{\text {a }}$ Drop-out after 1 st baseline $(n=135)$ was mainly due to staff resignations ( $62 \%$ of drop-out), but also to maternity/parental leave (12\%), long-term sickness leave (4\%), retirement (2\%), moved to protected-environment unit $(1 \%)$ or died $(1 \%)$; while $18 \%$ failed to complete baseline and final questionnaires.

Figure 3 Flow chart of nursing home staff participation in the reminiscence study.

It is possible that reminiscence only has short-term effects (i.e. in the hours immediately after the session) that are not apparent in the assessment of residents' more general health status, functioning and well-being [39]. Other possible explanations of the relatively modest effects of reminiscence are discussed below.

\section{i) Other factors may have overshadowed the effect from} reminiscence

The randomisation process attempted to adjust for differences between the two groups with respect to nursing home size, location and type. It was impossible, however, to adjust for possible differences in e.g. work culture, 
Table 4: Results of mixed modelling analysis of MBI and SF-12v2 scores for staff in the Intervention and Control Groups.

\begin{tabular}{|c|c|c|c|c|c|}
\hline & $\begin{array}{c}\text { MBI-PA } \\
\text { (Personal } \\
\text { accomplishment) }\end{array}$ & $\begin{array}{c}\text { MBI-EE } \\
\text { (Emotional } \\
\text { exhaustion) }\end{array}$ & $\begin{array}{c}\text { MBI - DPM } \\
\text { (Depersonalis- } \\
\text { ation) }\end{array}$ & $\begin{array}{c}\text { SF-12v2 PCS } \\
\text { (Physical } \\
\text { component) }\end{array}$ & $\begin{array}{l}\text { SF-12v2 MCS } \\
\text { (Mental } \\
\text { component) }\end{array}$ \\
\hline BL1 & $-1.0(-0.7 ; 0.5)$ & $-0.8(-1.6 ; 0.1)$ & $-0.2(-0.5 ; 0.1)$ & $0.9(0.1 ; 1.7)$ & $-0.9(-1.9 ; 0.0)$ \\
\hline BL3 & Reference & Reference & Reference & Reference & Reference \\
\hline T6 & $-0.5(-1.3 ; 0.4)$ & $1.5(0.3 ; 2.7)$ & $0.1(-0.4 ; 0.6)$ & $0.3(-0.9 ; 1.4)$ & $-1.9(-3.3 ;-0.6)$ \\
\hline T12 & $-0.5(-1.3 ; 0.4)$ & $1.1(-0.1 ; 2.4)$ & $0.1(-0.4 ; 0.6)$ & $-0.6(-1.7 ; 0.6)$ & $-0.7(-2.1 ; 0.7)$ \\
\hline iv & $-0.6(-1.7 ; 0.5)$ & $2.1(0.4 ; 3.9)$ & $0.7(0.0 ; 1.3)$ & $0.7(-0.8 ; 2.3)$ & $-1.6(-3.2 ;-0.0)$ \\
\hline T6*iv & $1.5(0.4 ; 2.7)$ & $-2.3(-4.0 ;-0.6)$ & $-0.8(-1.4 ;-0.1)$ & $-1.3(-2.9 ; 0.2)$ & $1.9(0.0 ; 3.8)$ \\
\hline T12*iv & $0.0(-1.2 ; 1.2)$ & $-2.1(-3.8 ;-0.3)$ & $-0.3(-1.0 ; 0.4)$ & $-0.0(-1.7 ; 1.6)$ & $1.3(-0.7 ; 3.3)$ \\
\hline Constant & $42.4(41.5 ; 43.2)$ & $11.5(10.2 ; 12.8)$ & $2.1(1.6 ; 2.5)$ & $50.9(49.7 ; 52.1)$ & $53.6(52.4 ; 54.9)$ \\
\hline $\mathrm{n}$ (obs/residents) & $999 / 344$ & $999 / 344$ & $999 / 344$ & $999 / 344$ & $999 / 344$ \\
\hline $\begin{array}{l}\text { Log-restricted } \\
\text { likelihood }\end{array}$ & -2947.7 & -3361.3 & -2405.4 & -3270.9 & -3390.1 \\
\hline
\end{tabular}

Figures are modelled parameter estimates (95\% confidence intervals).

$\mathrm{BL} 1=$ indicator for baseline $1 ; \mathrm{BL} 2=$ indicator for baseline $2 ; \mathrm{BL} 3=$ indicator for baseline $3 ; \mathrm{T} 6=$ indicator for $\mathrm{t}=6 \mathrm{months}$ after start of intervention; $\mathrm{T} 12$ = indicator for $\mathrm{t}=12$ months after start of intervention; iv = indicator for intervention group; T6iv = interaction between T6 and iv; T12iv = interaction between T12 and iv.

cooperation between staff groups, attitudes towards and expectations for residents. Despite a request to the nursing homes to avoid major organisational changes, these were sometimes unavoidable (e.g. new director, altered work routines) and for some months during the study there was negative national press coverage about the general quality of care in Danish nursing homes. Furthermore, the Danish public sector underwent a major structural reform in January 2007, although the nursing home managers judged its impact on the daily life of residents and staff to be limited.

\section{ii) The measurement instruments may have been} inappropriate

Reminiscence may influence aspects of resident and staff well-being that were not captured by the instruments

Table 5: Results of mixed modelling analysis of four SNCW factors for residents in the Intervention and Control Groups.

\begin{tabular}{|c|c|c|c|c|}
\hline & $\begin{array}{c}\text { Professional role and } \\
\text { development }\end{array}$ & $\begin{array}{l}\text { Work environment \& } \\
\text { staff collaboration }\end{array}$ & $\begin{array}{l}\text { Attitude towards } \\
\text { residents' level of care }\end{array}$ & $\begin{array}{l}\text { Attitude towards } \\
\text { contact with residents }\end{array}$ \\
\hline BL1 & $-0.0(-0.2 ; 0.2)$ & $0.1(-0.1 ; 0.2)$ & $-0.0(-0.2 ; 0.1)$ & $0.1(-0.1 ; 0.2)$ \\
\hline BL3 & Reference & Reference & Reference & Reference \\
\hline T6 & $0.2(-0.1 ; 0.6)$ & $-0.0(-0.3 ; 0.2)$ & $-0.2(-0.4 ;-0.0)$ & $0.1(-0.2 ; 0.3)$ \\
\hline T12 & $0.5(0.2 ; 0.9)$ & $0.0(-0.2 ; 0.3)$ & $-0.0(-0.2 ; 0.2)$ & $-0.0(-0.2 ; 0.2)$ \\
\hline iv & $0.3(-0.1 ; 0.8)$ & $0.5(0.2 ; 0.8)$ & $0.2(0.0 ; 0.4)$ & $0.2(-0.1 ; 0.5)$ \\
\hline T6*iv & $-0.0(-0.5 ; 0.4)$ & $0.0(-0.3 ; 0.4)$ & $-0.0(-0.3 ; 0.2)$ & $-0.4(-0.7 ;-0.1)$ \\
\hline T12*iv & $-0.5(-1.0 ;-0.1)$ & $-0.3(-0.7 ; 0.0)$ & $-0.2(-0.5 ; 0.0)$ & $-0.2(-0.6 ; 0.1)$ \\
\hline Constant & $3.1(2.8 ; 3.5)$ & $2.1(1.9 ; 2.3)$ & $1.5(1.4 ; 1.7)$ & $2.6(2.3 ; 2.8)$ \\
\hline n(obs/residents) & $1076 / 350$ & $1076 / 350$ & $1076 / 350$ & $1076 / 350$ \\
\hline $\begin{array}{l}\text { Log-restricted } \\
\text { likelihood }\end{array}$ & -2215.5 & -1843.8 & -1541.8 & -1795.3 \\
\hline
\end{tabular}

Figures are modelled parameter estimates ( $95 \%$ confidence intervals).

$\mathrm{BL} 1=$ indicator for baseline $1 ; \mathrm{BL} 2=$ indicator for baseline $2 ; \mathrm{BL} 3=$ indicator for baseline $3 ; \mathrm{T} 6=$ indicator for $\mathrm{t}=6 \mathrm{months}$ after start of intervention; T12 = indicator for $\mathrm{t}=12$ months after start of intervention; iv = indicator for intervention group; T6iv = interaction between T6 and iv; T12iv = interaction between T12 and iv. 
used. These instruments were selected on the basis of previous use in similar (Danish) contexts, evidence for acceptable psychometric properties and expectations that they would capture changes of interest. Assessment of resident cognition, behaviour and quality of life is not straightforward, however, and may be affected by background factors, e.g. educational level, physical health state, level of dementia [40,41]. In the current context the instruments showed high completion rates, good testretest reliability and expected correlations between instruments (data not shown). Furthermore, the general deterioration observed over time in the residents' level of functioning has been seen in previous studies of nursing home residents and elderly with dementia e.g. with respect to ADRQL [42], GBS [27] and SIB-S [43]. Only a subset of the items in the Swedish SNCW instrument (Satisfaction with Nursing Care and Work Assessment) were used in the current study and these items were furthermore categorised into four dimensions using factor analysis; the results for this instrument are thus not directly comparable to those from other studies using the SNCW.

\section{iii) Aspects of the RCT design}

Application of the RCT approach can be difficult for dynamic interventions where context is an important factor in determining whether and how an intervention will work, and where methodological issues arise related to size of target population, duration of follow-up and attrition [44]. Although the RCT design worked well overall there were some difficulties e.g. recruitment of nursing homes, uncertainty surrounding calculation of the necessary sample size (which instrument to use as a basis for calculation; sample included all residents, not only those with dementia), study participants were not blinded to randomisation group as is desirable in an RCT, and there were high drop-out rates for residents and staff - although this was expected from previous studies [42,45].

\section{iv) Reminiscence was not fully implemented in each site}

Although the staff at each IG site were interested and willing to implement reminiscence, and used it to a large extent in every day care, it was the project group's general impression that the staff in many places lacked resources to make full use of the knowledge gained through the course.

The main reasons for a less than full implementation appeared to be:

- Lack of time to plan and use general and specific reminiscence

- Insufficient support from management, in that staff would have wanted more regular discussion of reminiscence activities at staff meetings, greater participation of management personnel in the training course, and more visible praise for those who were active with reminiscence

- Lack of interest in learning about and using reminiscence due to a lack of recognition of the importance of residents' social and emotional needs. There can be a belief that it is not possible for the nursing home to improve the individual resident's quality of life e.g. because of the necessary daily routines, general lack of privacy and insufficient staff numbers; in addition there is often a tendency to focus on physical well-being and treatment rather than psychological well-being and quality of life [46]. Changing the approach to nursing home care is a complex undertaking that often requires a shift from a routine task-oriented day to more holistic and flexible care centred on quality of life [47].

- Implementation in a research context: the reminiscence training was purposely similar for all five nursing homes in an attempt to make the intervention as similar as possible; it would otherwise have been natural to tailor the activities more specifically to the individual nursing home. Some 'golden opportunities' to exploit the potential in the reminiscence method were thus not followed up e.g. for some individual residents, refurnishing of communal areas, contact to local voluntary workers and agencies.

When the study began, not all residents in the IG nursing homes had their life histories documented, and where these were documented, there was uncertainty about how they could be used in routine care. It was the reminiscence trainer's hope that the relatives would be active contributors to improving the documentation of residents' life histories, but this was seldom the case. Only a few relatives began to consider how they could convey information about the resident's habits and interests to the nursing home staff, and these were typically those relatives who had previously discussed these issues with the staff. This did not appear to be due to a lack of interest in the resident's well-being, but more a lack of time and resources on the relatives' side. The reminiscence exhibitions were, however, very successful in drawing relatives to the nursing homes, and many relatives expressed surprise at the extent of reminiscence activities and their influence on the residents' behaviour.

While it would appear that reminiscence can be implemented into the daily life and routine of a nursing home, a full implementation of the method requires visible support from management, staff recognition of the importance of residents' social and emotional needs, time and energy to plan reminiscence activities, as well as varied types of reminiscence materials. Further studies would be useful to investigate whether particular groups of residents (e.g. with respect to cognitive level, social needs) or staff (e.g. age, ethnic background, prioritising of care 
duties) can gain most from reminiscence; how residents perceive reminiscence activities; whether other forms of reminiscence implementation can give more effective implementation; the nature of the relationship between the immediate short-lived effects of reminiscence sessions and any longer-term effects.

\section{Limitations of the study}

The extent to which the participating nursing homes were representative of Danish nursing homes is unknown, although they did include examples of the different types of nursing home found in Denmark with respect to layout, size and general approach to nursing care. As expected, the drop-out rate among residents was high and mainly due to death. There was an element of self-selection bias due to the requirement of nursing homes/municipalities to be willing and able to participate in a research study with the extra burden of new learning and data collection and to provide self-financing. It is also possible that, despite the randomised matched approach, there were still variations between the two groups with respect to the daily environment and work culture.

Bias can have arisen from the nursing staff acting as proxy respondents for residents with respect to the assessment of the residents' functional level, agitated behaviour and quality of life (nursing staff also provided information on residents' sociodemographic and clinical details). The staff assessments may not have reflected the residents' true functional level - there is evidence that proxy responses are not always consistent with patient assessments, especially in relation to more subjective aspects such as emotional functioning and quality of life [48-50]. Furthermore, a resident could be assessed by different staff throughout the study. This bias is not considered to be of high significance, however, as $87 \%$ and $75 \%$ of the staff at the 6-month and 12-month follow-ups, respectively, had assessed the resident at baseline; furthermore, $70 \%$ and $95 \%$ of the staff at baseline and 12 months follow-up, respectively, had been primary carer for the resident for at least 6 months prior to making the assessment.

The reminiscence approach used here was broader than the typical, in that all staff were taught in all three forms (spontaneous, specific and general); all residents (both with and without dementia) were included in the reminiscence activities and the residents' relatives were strongly encouraged to actively participate. The training course was also atypical in that five nursing homes were taught simultaneously (rather than one at a time), and there were more frequent follow-up visits by the reminiscence trainers, e.g. to deliver reminiscence boxes and explain their content and potential use.

\section{Conclusions}

The results from this randomised intervention study indicate that the use of reminiscence has little long-term effect on residents of nursing homes. However, the nursing staff in the Intervention Group experienced greater satisfaction with professional roles and developed a more positive view of the residents and of their work environment. It would seem that reminiscence activities can help staff to view residents in a more personal light, with greater recognition of previous life experiences, and thus offer opportunities for more regular engagement in mutually enjoyable social activities.

\section{Competing interests}

All authors declare that the answer to the questions on the competing interest form are all No and therefore have nothing to declare.

\section{Authors' contributions}

As the primary reminiscence trainer, MK developed the reminiscence course and material and ran the training courses. AMJ was responsible for recruitment of nursing homes and implementation of reminiscence, in particular the use of reminiscence boxes, posters and exhibitions. $\mathrm{CG}$ and $\mathrm{CH}$ contributed to study design and were responsible for data collection, analysis and reporting. JS contributed to study design, data analysis and reporting. All authors read and approved the final manuscript.

\section{Acknowledgements}

The project received financial support from the Social Services Board of the Ministry for Social Affairs (the current Ministry of Welfare). The participating nursing homes have also contributed financially to the study by providing extra staff coverage while the permanent nursing staff were attending the reminiscence training course. The full study is described in a Danish book. The publisher has given permission to publish this material in English.

The authors thank the staff, residents and relatives from the ten nursing homes in the Mid-Jutland Region for their participation in reminiscence implementation and data collection, as well as the project interviewers for their role in data collection. The authors are also grateful to the following people for their general support of the study as well as contributions to study design and data interpretation: the members of the project's Steering Group, Ove Dahl (Nørrebro Erindringscenter - the Danish Centre for Reminiscence), Birgit Vinge (Kulturremisen, Brande) and Mette Birk-Olsen (CAST). The funding body, represented by Jørgen Løkkegaard, contributed to study design and provided support in the recruitment of nursing homes.

The project was registered with the Danish Data Protection Agency (no. 200541-4870). As the study was undertaken as part of routine care, with the addition only of staff-completed questionnaires and no collection of biological samples, ethical approval for the study was not required according to the Danish regulations. The study is registered with the International Standard Randomised Controlled Trial Number Register: ISRCTN90253170.

\section{Author Details}

${ }^{1}$ CAST - Centre for Applied Health Services Research \& Technology Assessment, University of Southern Denmark, J.B. Winsløws Vej 9B, 5000 Odense C, Denmark , 2Research and Development Division, VIOLA - Centre for the Life and Care of Elders, VIA University College, Campus Holstebro, GI. Struervej 1, 7500

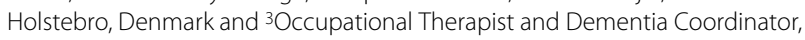
Rødovre Municipality, Rødovre Parkvej 150, 2610 Rødovre, Denmark

Received: 1 September 2009 Accepted: 6 June 2010 Published: 6 June 2010

\section{References}

1. Arlien-Søborg P, Rogowski P: [Forget-me-not: diagnosis of and intervention for nursing home residents with symptoms of dementia-a projekt undertaken at Haandværkerforenings Nursing Home, Copenhagen]. Copenhagen 2000. 
2. Kitwood T: Dementia reconsidered: the person comes first Buckingham: Open University Press; 1997.

3. The Reminiscence Centre in Ringkjøbing County: collaboration with services for the care for the elderly Reminiscence Centre in Ringkjøbing County; 2003

4. Butler R: The life review: an interpretation of reminiscence in the aged. Psychiatry 1963, 26:65-76.

5. Erikson E: Identity and the life cycle New York: International Universities Press; 1959.

6. Burnside I, Haight BK: Reminiscence and life review: analysing each concept. J Adv Nurs 1992, 17:855-862.

7. Kasl-Godley J, Gatz M: Psychosocial interventions for individuals with dementia: an integration of theory, therapy, and a clinical understanding of dementia. Clin Psychol Rev 2000, 20:755-782

8. $L$ in $Y C$, Dai $Y T$, Hwang $S L$ : The effect of reminiscence on the elderly population: a systematic review. Public Health Nurs 2003, 20:297-306

9. Gibson F: What can reminiscence contribute to people with dementia? In Reminiscence reviewed: perspectives, evaluations, achievements Edited by: Bornat J. Open University Press; 1995

10. Bohlmeijer $E$, Smit $F$, Cuijpers $P$ : Effects of reminiscence and life review on late-life depression: a meta-analysis. Int J Geriatr Psychiatry 2003, 18:1088-1094

11. Boller F, Verny M, Hugonot-Diener L, Saxton J: Clinical features and assessment of severe dementia: a review. Eur J Neurol 2002, 9:125-136.

12. Woods B, Spector A, Jones C, Orrell M, Davies S: Reminiscence therapy for dementia. Cochrane Database Syst Rev 2005:CD001120.

13. Baillon S, Van Diepen E, Prettyman R, Redman J, Rooke N, Campbell R: A comparison of the effects of Snoezelen and reminiscence therapy on the agitated behaviour of patients with dementia. Int J Geriatr Psychiatry 2004, 19:1047-1052.

14. Bornat J, Chamberlayne P: Reminiscence in care settings: implications for training. Educ Ageing 1999, 14:277-295.

15. Schrijnemaekers VJ, van Rossum E, Candel MJ, Frederiks CM, Derix MM, Sielhorst $\mathrm{H}$, van den Brandt PA: Effects of emotion-oriented care on work-related outcomes of professional caregivers in homes for elderly persons. J Gerontol B Psychol Sci Soc Sci 2003, 58:S50-S57.

16. Finnema E, Droes RM, Ettema T, Ooms M, Ader H, Ribbe M, Van Tilburg W: The effect of integrated emotion-oriented care versus usual care on elderly persons with dementia in the nursing home and on nursing assistants: a randomized clinical trial. Int J Geriatr Psychiatry 2005, 20:330-343

17. Baines $S$, Saxby $P$, Ehlert $K$ : Reality orientation and reminiscence therapy: a controlled cross-over study of elderly confused people. Br J Psychiatry 1987, 151:222-231.

18. Jonsdottir H, Jonsdottir G, Steingrimsdottir E, Tryggvadottir B: Group reminiscence among people with end-stage chronic lung diseases. Adv Nurs 2001, 35:79-87.

19. Brodaty H, Ames D, Snowdon J, Woodward M, Kirwan J, Clarnette R, Lee E, Lyons B, Grossman F: A randomized placebo-controlled trial of risperidone for the treatment of aggression, agitation, and psychosis of dementia. J Clin Psychiatry 2003, 64:134-143.

20. Finkel SI, Lyons JS, Anderson RL: Reliability and validity of the CohenMansfield Agitation Inventory in institutionalized elderly. Int J Geriatr Psychiatry 1992, 7:487-490

21. Birk-Olsen M: Questionnaire study of characteristics of nursing homes in Ringkobing County Odense: CAST-Centre for Health Services Research and Technology Assessment, University of Southern Denmark; 2004.

22. Cohen-Mansfield J, Marx MS, Rosenthal AS: A description of agitation in a nursing home. J Gerontol 1989, 44:M77-M84

23. Manfredi PL, Breuer B, Wallenstein S, Stegmann M, Bottomley G, Libow L: Opioid treatment for agitation in patients with advanced dementia. Int J Geriatr Psychiatry 2003, 18:700-705.

24. Abelskov K: Assessment of behavioural disturbances. Hosp Health Care Online 2007, 6:

25. Rabins PV, Kasper JD, Kleinman L, Black BS, Patrick DL: Concepts and methods in the development of the ADRQL: an instrument for assessing health-related quality of life in persons with Alzheimer disease. J Ment Health Ageing 1999, 5:33-48.

26. Gudex C, Horsted C: Translation of the Alzheimer Disease Related Quality of Life $^{\text {TM }}\left(A D R Q L^{\mathrm{TM}}\right)$ instrument into Danish Odense: CAST - Center for Anvendt Sundhedstjenesteforskning og Teknologivurdering, Syddansk Universitet; 2005.
27. Bråne G, Gottfries CG, Winblad B: The Gottfries-Bråne-Steen Scale: validity, reliability and application in anti-dementia drug trials. Dement Geriatr Cogn Disord 2001, 12:1-14

28. Folstein MF, Folstein SE, Mchugh PR: 'Mini-Mental State': a practical method for grading cognitive state of patients for the clinician. Psychiatr Res 1975, 12:189-198.

29. Saxton J, Boller F, Miller M, Swihart AA, McGonigle-Gibson KL: Assessment of the severely impaired patient: description and validation of a new neuropsychological test battery. Psychol Assess 1990, 2:298-303.

30. Saxton J, Kastango KB, Hugonot-Diener L, Boller F, Verny M, Sarles CE, Girgis RR, Devouche E, Mecocci P, Pollock BG, et al.: Development of a short form of the severe impairment battery. Am J Geriatr Psychiatry 2005, 13:999-1005.

31. Maslach C, Jackson SE: The measurement of experienced burnout. $J$ Occup Behav 1981, 2:99-113.

32. Berg A, Hallberg IR: Effects of systematic clinical supervision on psychiatric nurses' sense of coherence, creativity, work-related strain, job satisfaction and view of the effects from clinical supervision: a prepost test design. J Psychiatr Ment Health Nurs 1999, 6:371-381.

33. Hallberg IR, Welander-Hansson U, Axelsson K: Satisfaction with nursing care and work during a year of clinical supervision and individualised care: comparison between two wards for care of severely demented patients. J Nurs Manag 1994, 1:297-307.

34. Ware J Jr, Kosinski M, Keller SD: A 12-Item Short-Form Health Survey: construction of scales and preliminary tests of reliability and validity. Med Care 1996, 34:220-233.

35. Gandek B, Ware JE, Aaronson NK, Apolone G, Bjørner JB, Brazier JE, Bullinger M, Kaasa S, Leplege A, Prieto L, et al:: Cross-validation of item selection and scoring for the SF-12 Health Survey in nine countries: results from the IQOLA Project International Quality of Life Assessment. J Clin Epidemiol 1998, 51:1171-1178.

36. Cheng J, Edwards LJ, Maldonado-Molina MM, Komro KA, Muller KE: Real longitudinal data analysis for real people: Building a good enough mixed model. Statistics in Medicine 2010, 29:504-520.

37. Gibbons RD, Hedeker D, Toit SD: Advances in Analysis of Longitudinal Data. Annual Review of Clinical Psychology 2010, 6:3.1-3.29.

38. Gardiner JC, Luo Z, Roman LA: Fixed effects, random effects and GEE: what are the differences? Stat Med 2009, 28:221-239.

39. Sansom G, Coleman M, Young I, Pope P, Richards C: Effectiveness of using a multisensory environment versus themed reminiscence to enhance the well-being of people with dementia. J Dement Care 2002, 10:38.

40. Abraham IL, Manning CA, Snustad DG, Brashear HR, Newman MC, Wofford $A B$ : Cognitive screening of nursing home residents: factor structures of the Mini-Mental State Examination. J Am Geriatr Soc 1994, 42:750-756.

41. Ettema TP, Droes RM, de Lange J, Mellenbergh GJ, Ribbe MW: A review of quality of life instruments used in dementia. Qual Life Res 2005, 14:675-686

42. Lyketsos CG, Gonzales-Salvador T, Chin JJ, Baker A, Black B, Rabins P: A follow-up study of change in quality of life among persons with dementia residing in a long-term care facility. Int I Geriatr Psychiatry 2003, 18:275-281.

43. Wild KV, Kaye JA: The rate of progression of Alzheimer's disease in the later stages: evidence from the Severe Impairment Battery. J Int Neuropsychol Soc 1998, 4:512-516.

44. Andrieu S, Coley N, Aisen P, Carrillo MC, Dekosky S, Durga J, Fillit H, Frisoni $G B$, Froelich L, Gauthier S, et al: Methodological issues in primary prevention trials for neurodegenerative dementia. J Alzheimers Dis 2009, 16:235-270

45. Spector A, Thorgrimsen L, Woods B, Royan L, Davies S, Butterworth M, Orrell M: Efficacy of an evidence-based cognitive stimulation therapy programme for people with dementia: randomised controlled trial. $\mathrm{Br}$ J Psychiatry 2003, 183:248-254.

46. Kane RA: Definition, measurement, and correlates of quality of life in nursing homes: toward a reasonable practice, research, and policy agenda. Gerontologist 2003, 43(Spec No 2):28-36.

47. Kovach CR, Krejci JW: Facilitating change in dementia care: staff perceptions. J Nurs Adm 1998, 28:17-27.

48. Karlawish JHT, Casarett D, Klocinski J, Clark CM: The relationship between caregivers' global ratings of Alzheimer's disease patients' quality of life, disease severity, and the caregiving experience. J Am Geriatr Soc 2001, 49:1066-1070 
49. Naglie G, Tomlinson G, Tansey C, Irvine J, Ritvo P, Black SE, Freedman M, Silberfeld M, Krahn M: Utility-based Quality of Life measures in Alzheimer's disease. Qual Life Res 2006, 15:631-643.

50. Kutner JS, Bryant LL, Beaty BL, Fairclough DL: Symptom distress and quality-of-life assessment at the end of life: the role of proxy response. J Pain Symptom Manage 2006, 32:300-310.

Pre-publication history

The pre-publication history for this paper can be accessed here: http://www.biomedcentral.com/1471-2318/10/33/prepub

doi: $10.1186 / 1471-2318-10-33$

Cite this article as: Gudex et al., Consequences from use of reminiscence - a randomised intervention study in ten Danish nursing homes BMC Geriatrics 2010, 10:33

Submit your next manuscript to BioMed Central and take full advantage of:

- Convenient online submission

- Thorough peer review

- No space constraints or color figure charges

- Immediate publication on acceptance

- Inclusion in PubMed, CAS, Scopus and Google Scholar

- Research which is freely available for redistribution

Submit your manuscript at www.biomedcentral.com/submit 